\title{
Mortality trends and the impact of lymphadenectomy on survival for renal cell carcinoma patients with distant metastasis
}

\author{
Hiten D. Patel, MD; Michael A. Gorin, MD; Natasha Gupta, MD; Max Kates, MD; Michael H. Johnson, MD; \\ Phillip M. Pierorazio, MD; Mohamad E. Allaf, MD
}

James Buchanan Brady Urological Institute, Johns Hopkins Medical Institutions, Baltimore, MD, United States

Cite as: Can Urol Assoc J 2016;10(11-12):389-95. htrp://dx.doi.org/10.5489/cuaj.1999

See related commentary on page 396.

\section{Abstract}

Introduction: Current treatment paradigms for metastatic renal cell carcinoma (mRCC) invoke a combination of surgical and systemic therapies. We sought to quantify trends in mortality and performance of lymphadenectomy, as well as impact on survival for patients with mRCC.

Methods: The Surveillance, Epidemiology, and End Results registry (SEER) (1988-2011) identified patients with mRCC. Kaplan-Meier curves and Cox proportional hazards models with competing risks regression were employed to assess survival.

Results: 15060 patients with mRCC were identified, with 6316 $(41.9 \%)$ undergoing cytoreductive nephrectomy. Mean number of lymph nodes removed was 6.2 , with mean 3.3 positive nodes among 1018 (43.9\%) patients with positive nodes. Median overall survival (OS) increased from seven to 11 months (1999-2010), and finding a positive node decreased median cancer survival from 22 to nine months. Cancer-specific survival (CSS) showed significant decreases in mortality after 2005 (hazard ratio [HR] 0.71 [0.60-0.83] comparing 2010 to 1990). Lymphadenectomy was associated with decreased OS (HR 1.10 [1.03-1.16]; $\mathrm{p}=0.002)$ due to decreased CSS (HR 1.10 [1.04-1.17]; $p<0.001)$ without increase in other-cause mortality (HR 0.94 [0.79-1.11]; $p=0.455)$. However, more extensive lymphadenectomy $\geq 3$ lymph nodes removed did not significantly impact OS or CSS. Number of positive lymph nodes was associated with decreased CSS.

Conclusions: mRCC continues to carry a poor prognosis, but current treatment paradigms have led to modest improvements in OS and CSS in recent years. Lymphadenectomy was found to play a prognostic rather than therapeutic role in the management of mRCC. The performance of lymphadenectomy should be limited based on clinical judgment and better incorporated into randomized trials of new systemic therapies to identify scenarios where implementation may improve survival.

\section{Introduction}

A quarter of patients with renal cell carcinoma (RCC) present with distant metastatic disease at the time of diagnosis. ${ }^{1}$ Current treatment paradigms invoke an integration of surgical and systemic therapies to optimize survival, but a number of controversies persist. ${ }^{2}$ Cytoreductive nephrectomy $(\mathrm{CN})$ before systemic therapy has been the dominant treatment paradigm since 2001. A combined analysis of two randomized trials showed longer median survival for $\mathrm{CN}$ preceding immunotherapy (interferon-alpha) compared to immunotherapy alone (13.6 vs. 7.8 months).$^{3-5}$ While preoperative selection is necessary for surgery, based on performance status and other factors identified by Culp et al, both $\mathrm{CN}$ and metastasectomy appear to play potential therapeutic roles in the management of metastatic RCC ( $m R C C) .2,6,7$ Less certain, however, is whether the performance of lymphadenectomy (LND) at the time of $\mathrm{CN}$ exerts an effect on survival.

Reviews of the literature and available randomized trial data suggest LND plays a therapeutic role in clinical nodal disease without distant metastasis, but that it is not generally therapeutic for pT1-2 disease and has an uncertain effect in localized high-risk disease (T3-4N0M0). ${ }^{8,9}$ Minimal data is available on the role of LND in $\mathrm{mRCC}$, with a general belief that there would be negligible, if any benefit at the cost of increased time and morbidity during surgery. It would then follow that LND may be expected to have no impact on cancer survival while possibly being detrimental to overall survival (OS). Therefore, we sought to quantify trends in mortality and the performance of LND for patients with mRCC before and after the implementation of systemic therapy, and assess the effect of LND on survival for patients diagnosed with mRCC. We hypothesized that LND for patients with mRCC would show no impact on cancer-specific survival (CSS) while increasing other-cause mortality. 
Patel et al.

\section{Methods}

\section{Study cohort, variables, and outcomes}

After obtaining Institutional Review Board approval, the Surveillance, Epidemiology, and End Results (SEER) registry was used to identify patients diagnosed with mRCC (M1 disease based on TNM stage) from 1988-2011. The time period allowed a number of years prior to and after the introduction of systemic therapy to assess trends. Demographics and clinical data were assessed, including age, sex, race, year of diagnosis, surgical treatments (CN and LND), radiation therapy, tumour size, and Fuhrman grade. If LND was performed, the number of lymph nodes (LNs) sampled, as well as number of positive LNs was determined. Followup began from the time of diagnosis, and outcomes to assess survival included any cause of death (OS) and RCC cause of death (CSS).

\section{Statistical analysis}

Absolute survival was tabulated using median survival, mean time to death, and Kaplan-Meier curves for survival probabilities. Survival was stratified by the overall cohort, patients receiving $\mathrm{CN}$ and/or LND, the number of positive LNs, and year of diagnosis. Relative survival was assessed using multivariable Cox proportional hazards models, along with sensitivity analyses restricting the cohort to $\mathrm{CN}$ patients and specific time periods. Sensitivity analyses also varied cutoffs for the number of LNs removed, defined as LND (directly reported are $\geq 1, \geq 3$, and $\geq 8$ based on a prior study ${ }^{10}$ ) given that the removal of one or very few $L N$ s could indicate a LN biopsy rather than attempt at formal LND. The final relative survival estimates employed competing risks regres- sion considering non-cancer causes of death (other-cause mortality) as a competing risk of death. Statistical analyses were performed using STATA software v.12.0 (STATA Corp, College Station, TX, U.S).

\section{Results}

A total of 15060 patients with mRCC met the inclusion criteria, with 6316 (41.9\%) undergoing $C N$, of which 2318 $(36.7 \%)$ also had at least one LN removed at the time of surgery (Appendix A). The concurrent removal of any LN increased from $26.1 \%$ in 1995 to $43.5 \%$ in $2009(+1.2 \%$ per year), but decreased somewhat to $37.4 \%$ in 2011 . Fig. $1 \mathrm{~A}$ shows LND over time defined as the removal of $\geq 3$ and $\geq 8$ LNs based on previous research. ${ }^{10}$ Using the strictest definition $(\geq 8)$, the performance of LND increased from about $2.3 \%$ in 1990 to about $5 \%$ in recent years. The mean number of LNs was 6.2 (7.9) for surgeries with at least one LN removed, and there was an average of 3.3 (4.3) positive LNs among the 1018 patients with positive nodes (Appendix B). Median overall survival increased about four months, from six to seven months before 1999 to 10 to 11 months after 2005, which paralleled improvement in CSS and one-year Kaplan-Meier survival probabilities (Fig. 1B). Cancer survival was about eight months for the overall cohort, 19 months for patients receiving a $\mathrm{CN}$, and 15 months for patients receiving $\mathrm{CN}$ along with LN sampling (Table 1). Among the latter group, patients found to have no positive nodes after surgery had a median cancer survival of 22 months, while survival decreased to nine months with the finding of any positive node. OS and CSS generally decreased with increasing number of positive LNs.

Relative CSS improved during the time period, with adjusted hazard ratios (HRs) over the years plotted in Fig. 1C showing significant improvement after 2005, with a HR

\begin{tabular}{|c|c|c|c|c|c|c|c|c|c|c|c|c|}
\hline & $\mathbf{N}$ & $\%$ & $\begin{array}{l}\text { Followup } \\
\text { (months) }\end{array}$ & Death & $\%$ & $\begin{array}{c}\text { Time to } \\
\text { death } \\
\text { (months) }\end{array}$ & SD & $\begin{array}{c}\text { RCC } \\
\text { death }\end{array}$ & $\%$ & $\begin{array}{c}\text { Time to } \\
\text { RCC death } \\
\text { (months) }^{\mathrm{a}}\end{array}$ & SD & $\begin{array}{c}\text { Median K-M } \\
\text { RCC survival } \\
\text { (months) }\end{array}$ \\
\hline Cohort & 15060 & 100.0 & 15.8 & 13026 & 86.5 & 12.2 & 19.5 & 11319 & 75.2 & 11.6 & 17.3 & 8 \\
\hline No LND & 12742 & 84.6 & 14.4 & 11199 & 87.9 & 11.3 & 18.7 & 9679 & 76.0 & 10.8 & 16.7 & 7 \\
\hline $\mathrm{CN}$ only & 3998 & 26.5 & 26.9 & 3106 & 77.7 & 21.0 & 25.9 & 2687 & 67.2 & 19.4 & 23.0 & 19 \\
\hline $\mathrm{CN}+\mathrm{LN}$ sampling & 2318 & 15.4 & 23.4 & 1827 & 78.8 & 17.6 & 23.2 & 1640 & 70.8 & 16.4 & 19.8 & 15 \\
\hline Any positive node & 1018 & 43.9 & 15.9 & 879 & 86.3 & 12.8 & 17.8 & 797 & 78.3 & 11.9 & 15.1 & 9 \\
\hline \multicolumn{13}{|l|}{ \# LNs positive } \\
\hline 0 & 1300 & 56.1 & 29.2 & 948 & 72.9 & 22.0 & 26.7 & 843 & 64.8 & 20.6 & 22.8 & 22 \\
\hline 1 & 454 & 19.6 & 18.8 & 383 & 84.4 & 14.7 & 19.8 & 344 & 75.8 & 13.6 & 17.5 & 10 \\
\hline 2 & 201 & 8.7 & 14.7 & 181 & 90.0 & 12.9 & 16.3 & 166 & 82.6 & 12.6 & 15.8 & 10 \\
\hline 3 & 110 & 4.7 & 15.7 & 94 & 85.5 & 13.1 & 24.3 & 83 & 75.5 & 10.3 & 10.8 & 9 \\
\hline $4+$ & 253 & 10.9 & 11.7 & 230 & 90.9 & 9.2 & 8.8 & 204 & 80.6 & 9.2 & 9.1 & 8 \\
\hline
\end{tabular}

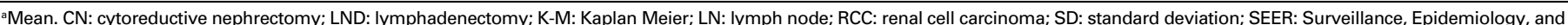
End Results registry. 
of 0.71 (0.60-0.83) comparing 2010 to 1990 . The adjusted overall competing risks survival model showed a significant decrease in survival associated with removal of $\geq 1 \mathrm{LN}$ (HR 1.10 [1.03-1.16]; $p=0.002$ ). Removal of $\geq 1 \mathrm{LN}$ was not associated with decreased survival due to other causes (HR 0.94 [0.79-1.11]; $p=0.455)$, but was associated with decreased CSS (HR 1.10 [1.04-1.17]; $\mathrm{p}<0.001]$ (Table 2, Fig. 2A). However, higher threshold definitions for LND ( $\geq 3$ and $\geq 8$ ) more likely to estimate performance of a true LND did not show any difference in OS, other-cause survival, or CSS in competing risks models (Figs 2B, 2C; further sensitivity analyses and modes for variation in $\mathrm{LNs}$ removed are shown in Table 2). CSS with mRCC did not vary depending on age at diagnosis, but survival decreased for female sex, White race, and increasing primary tumour size. Subanalyses, including restriction to only $\mathrm{CN}$ patients and to patients diagnosed with $\mathrm{mRCC}$ in more recent years, showed the same associations for LND. Among patients undergoing LND, the number of positive LNs had the strongest association with decreased CSS, ranging from HR $1.56(1.37-1.77 ; \mathrm{p}<0.001)$ for one positive node to HR $2.30(1.96-2.70 ; p<0.001)$ for four or more positive nodes (Appendix C; Fig. 2D).

\section{Discussion}

Metastatic RCC continues to carry a poor prognosis despite advances in treatment paradigms over the past two decades. However, our results show modest improvements in OS and CSS in recent years. Integrating surgical and systemic therapies has been key to providing effective therapeutic options to patients with mRCC. ${ }^{2}$ This likely explains the increased survival rates for $\mathrm{mRCC}$ patients in SEER over the study period. While $\mathrm{CN}$ and metastasectomy are thought to have potential therapeutic roles and are often integrated in parallel with systemic therapy, the role of LND has been uncertain and inconsistently employed..$^{2,6-9,11}$ Our results suggest that LND does not play a therapeutic role for patients with $\mathrm{mRCC}$. The removal of any $\mathrm{LN}$ was associated with decreased OS. The reason for this detrimental effect was not due to increased other-cause mortality, as we had hypothesized, but was attributable to decreased CSS. However, this is likely due to selective sampling of suspicious nodes in some patient. A stricter definition for LND ( $\geq 3$ to $\geq 8 \mathrm{LNs}$ removed) to account for inadvertent or selective removal (biopsy) of LNs showed LND had no impact on OS, CSS, or other-cause mortality. The latter finding is considered to more accurately reflect performance of LND with clinical therapeutic intent.

Early evidence had suggested LND might play a therapeutic role in $\mathrm{mRCC}$, with a significant survival advantage in a study comparing 17 patients undergoing $C N$ to 112 patients undergoing $\mathrm{CN}$ and LND. ${ }^{12}$ However, a more recent mRCC cohort of 258 patients from Memorial Sloan Kettering

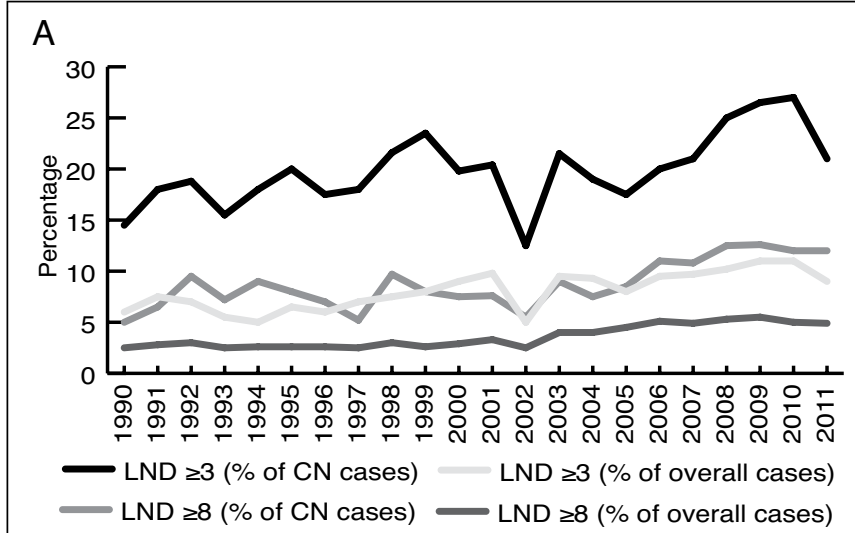

$\mathrm{B}$

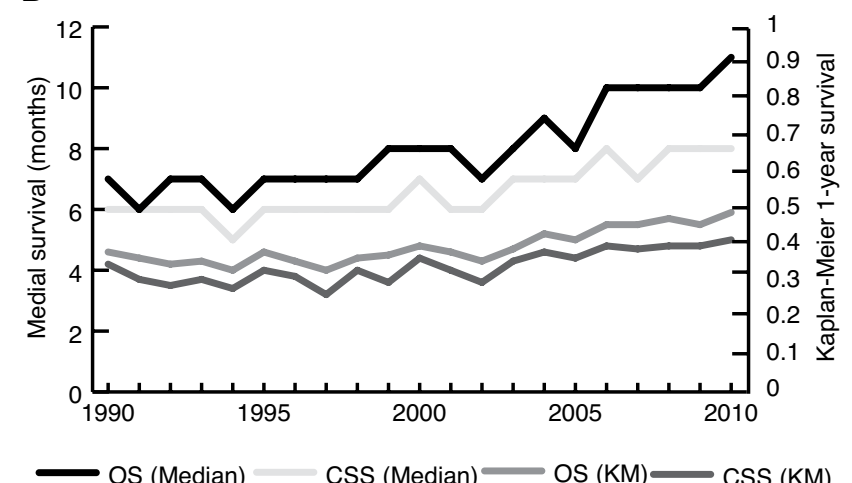

C

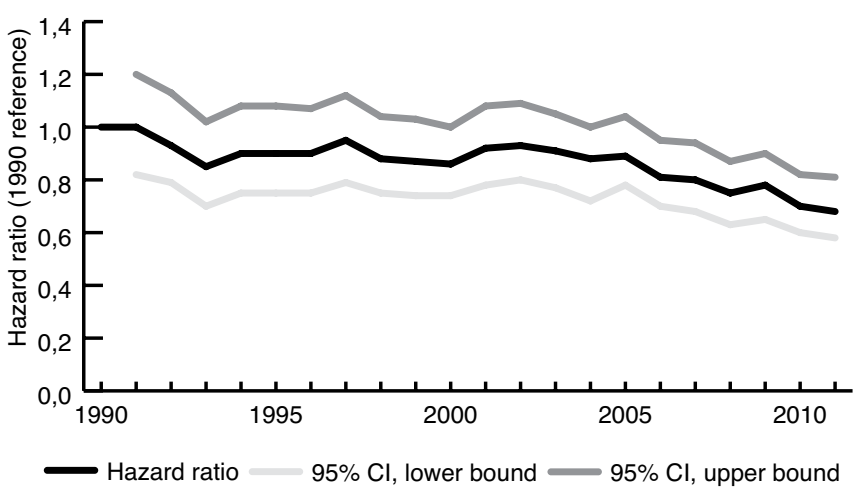

Fig. 1. Trends over time in $(\boldsymbol{A})$ the performance of lymphadenectomy (for definitions based on $\geq 3$ and $\geq 8$ lymph nodes removed); ( $\boldsymbol{B}$ ) median survival and Kaplan-Meier survival probabilities; and (C) adjusted cancer-specific survival for metastatic renal cell carcinoma patients, Surveillance, Epidemiology, and End Results registry 1988-2011. Cl: confidence interval; CSS: cancer-specific survival; LND: lymphadenectomy; OS: overall survival.

indicated LND did not provide a survival advantage, with a comparative five-year survival of $21 \%$ for patients undergoing $\mathrm{CN}$ with LND and $31 \%$ for patients undergoing $\mathrm{CN}$ without LND. ${ }^{10}$ Although survival was lower for patients undergoing LND, the difference was not significant due to small sample size. Furthermore, cause of death was not 


\begin{tabular}{|c|c|c|c|c|}
\hline & \multicolumn{4}{|c|}{$95 \% \mathrm{Cl}$} \\
\hline & HR & Low & High & p value \\
\hline \multicolumn{5}{|c|}{ Univariate model } \\
\hline$\geq 1 \mathrm{LN}$ & 0.66 & 0.63 & 0.70 & $<0.001$ \\
\hline$\geq 3 \mathrm{LN}$ & 0.65 & 0.61 & 0.69 & $<0.001$ \\
\hline$\geq 8 \mathrm{LN}$ & 0.66 & 0.60 & 0.72 & $<0.001$ \\
\hline \multicolumn{5}{|c|}{ Model 1: Multivariable ${ }^{a}$} \\
\hline$\geq 1 \mathrm{LN}$ & 0.71 & 0.67 & 0.75 & $<0.001$ \\
\hline$\geq 3 \mathrm{LN}$ & 0.72 & 0.67 & 0.77 & $<0.001$ \\
\hline$\geq 8 \mathrm{LN}$ & 0.73 & 0.66 & 0.81 & $<0.001$ \\
\hline \multicolumn{5}{|c|}{ Model 2: Multivariable ${ }^{b}$} \\
\hline$\geq 1 \mathrm{LN}$ & 1.12 & 1.05 & 1.19 & $<0.001$ \\
\hline$\geq 3 \mathrm{LN}$ & 1.06 & 0.99 & 1.14 & 0.11 \\
\hline$\geq 8 \mathrm{LN}$ & 1.04 & 0.95 & 1.15 & 0.39 \\
\hline \multicolumn{5}{|c|}{ Model 3: Competing risks ${ }^{c}$} \\
\hline$\geq 3 \mathrm{LN}$ & 1.03 & 0.96 & 1.10 & 0.42 \\
\hline $\mathrm{CN}$ & 0.51 & 0.49 & 0.53 & $<0.001$ \\
\hline \multicolumn{5}{|l|}{ Age } \\
\hline$<45$ & REF & - & - & - \\
\hline $45-54$ & 0.98 & 0.90 & 1.06 & 0.61 \\
\hline $55-64$ & 0.97 & 0.89 & 1.05 & 0.43 \\
\hline $65-74$ & 0.93 & 0.86 & 1.01 & 0.10 \\
\hline $75-84$ & 0.96 & 0.87 & 1.05 & 0.33 \\
\hline $85+$ & 0.96 & 0.83 & 1.11 & 0.57 \\
\hline \multicolumn{5}{|l|}{ Sex } \\
\hline Female & 1.08 & 1.04 & 1.13 & $<0.001$ \\
\hline \multicolumn{5}{|l|}{ Race } \\
\hline White & REF & - & - & - \\
\hline Black & 0.93 & 0.87 & 0.99 & 0.03 \\
\hline Hispanic & 0.90 & 0.85 & 0.96 & 0.00 \\
\hline Other & 0.87 & 0.80 & 0.94 & $<0.001$ \\
\hline \multicolumn{5}{|l|}{ Radiation } \\
\hline None & REF & - & - & - \\
\hline Therapy & 1.12 & 1.08 & 1.16 & $<0.001$ \\
\hline Unknown & 1.17 & 0.97 & 1.41 & 0.11 \\
\hline \multicolumn{5}{|l|}{ Tumour size } \\
\hline$\leq 4$ & REF & - & - & - \\
\hline$>4$ to $\leq 7$ & 1.20 & 1.11 & 1.30 & $<0.001$ \\
\hline$>7$ to $\leq 10$ & 1.36 & 1.26 & 1.46 & $<0.001$ \\
\hline$>10$ to $\leq 20$ & 1.51 & 1.40 & 1.63 & $<0.001$ \\
\hline$>20$ & 1.79 & 1.46 & 2.18 & $<0.001$ \\
\hline Unknown & 1.17 & 1.08 & 1.27 & $<0.001$ \\
\hline
\end{tabular}

specified to separate deaths due to cancer from other causes. Our analysis captures a larger population-based cohort and verifies more recent thoughts that LND may have negligible, if any benefit in mRCC.

Interestingly, we found other-cause mortality was comparable between groups even with variation in the extent of LND, while CSS was decreased for patients with a few LNs removed rather than equivalent, as initially expected. There

\begin{tabular}{|c|c|c|c|c|}
\hline & \multicolumn{4}{|c|}{$95 \% \mathrm{Cl}$} \\
\hline & HR & Low & High & p value \\
\hline \multicolumn{5}{|c|}{ Sensitivity analyses ${ }^{d}$} \\
\hline \multicolumn{5}{|l|}{ LND $^{d}$} \\
\hline$\geq 1$ node & 1.10 & 1.04 & 1.17 & $<0.001$ \\
\hline$\geq 2$ nodes & 1.07 & 1.01 & 1.14 & 0.03 \\
\hline$\geq 3$ nodes & 1.03 & 0.96 & 1.10 & 0.42 \\
\hline$\geq 4$ nodes & 0.99 & 0.93 & 1.07 & 0.84 \\
\hline \multicolumn{5}{|c|}{$\begin{array}{l}\text { aAdjusted for year, age, sex, race, radiation, and tumour size (not shown); not adjusted } \\
\text { for CN; badjusted for CN, year, age, sex, race, radiation, and tumour size (not shown); } \\
\text { 'competing risks model accounting for other-cause mortality and adjusted for CN, year, age } \\
\text { sex, race, radiation, and tumour size; 'dsensitivity analyses varying the cutoff for number of } \\
\text { nodes removed to qualify as a LND. Cl: confidence interval; CN: cytoreductive nephrectomy } \\
\text { HR: hazard ratio; LND: Iymphadenectomy; SEER: Surveillance, Epidemiology, and End } \\
\text { Results registry. }\end{array}$} \\
\hline
\end{tabular}

are a few possible explanations for this effect. One important reason could be a tendency to perform a LN biopsy on mRCC patients with a worse prognosis - choosing clinically suspicious LNs to resect intraoperatively, which would lead to identification of more advanced locoregional disease. While a validated model by Heng et al, the International Metastatic Renal-Cell Carcinoma Database Consortium prognostic model, now exists to stratify patients based on risk, SEER does not provide sufficient laboratory or performance data to compare patients based on risk groups..$^{13} \mathrm{~A}$ second explanation may be related to coding of the cause of death. Mortality incurred from the removal of LNs, either directly or indirectly due to postoperative morbidity, could be attributed to the cancer instead of iatrogenic etiology because of the fact the surgery was performed for mRCC. Our sensitivity analysis showed higher threshold definitions for $L N D$, such as $\geq 3$ or $\geq 8$ LNs removed, were not significantly associated with OS, CSS, or other-cause mortality. The data support the notion that LND may add minimal morbidity and be unlikely to translate into a significant detriment to survival among patients with mRCC. The findings are similar to those from EORTC 30881, although the trial was limited to patients without nodal or distant metastatic disease at presentation. ${ }^{8}$

Before the widespread implementation of systemic therapies, mortality for patients with mRCC was fairly static. The development of novel categories of systemic and targeted treatments for mRCC has led to improved cancer survival in recent years (2010 vs. 1990: HR 0.71 [0.60-0.83]; $p<0.001$ ). However, there is significant variation in prognosis leading to a need for prognostic models to help advise patients and determine the best options for therapy. Although LND does not appear to play a therapeutic role in the treatment of $\mathrm{mRCC}$, the number of positive nodes found during surgery does provide additional prognostic survival data that could aid in risk-stratification. The International Metastatic Renal-Cell Carcinoma Database Consortium prognostic 


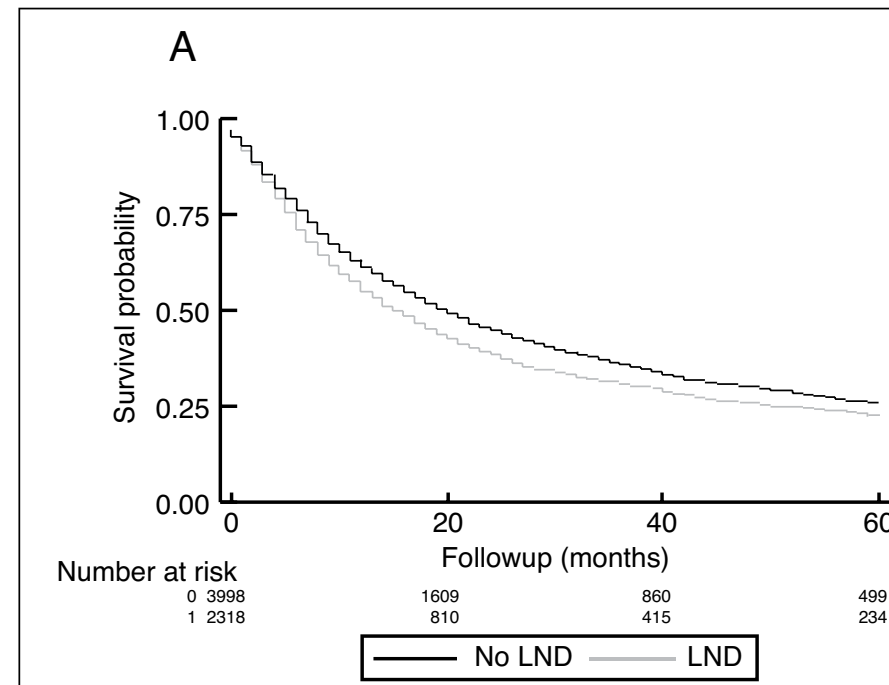

\section{B}

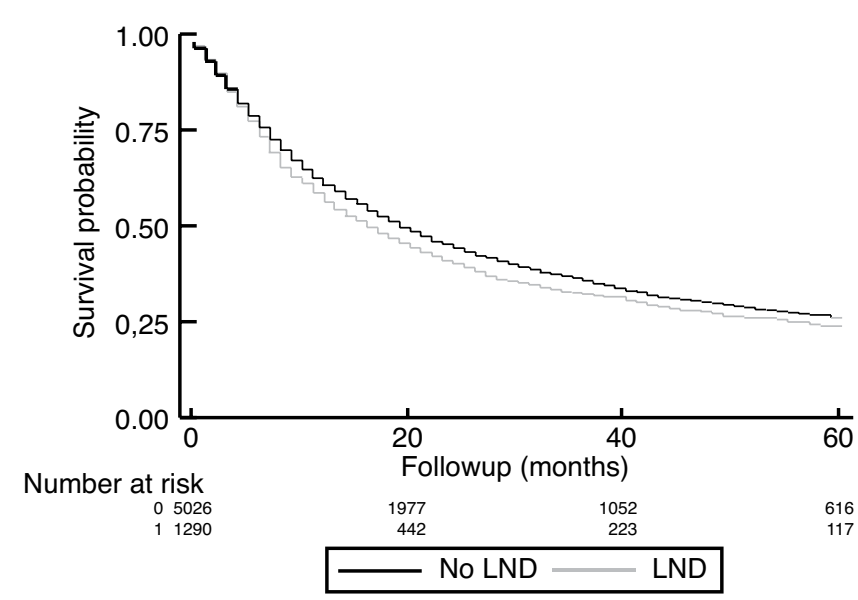

C

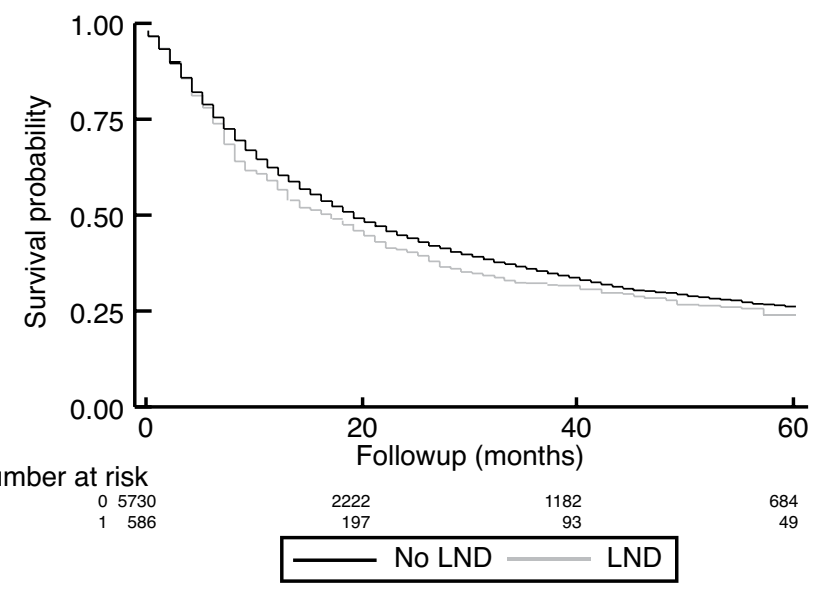

D

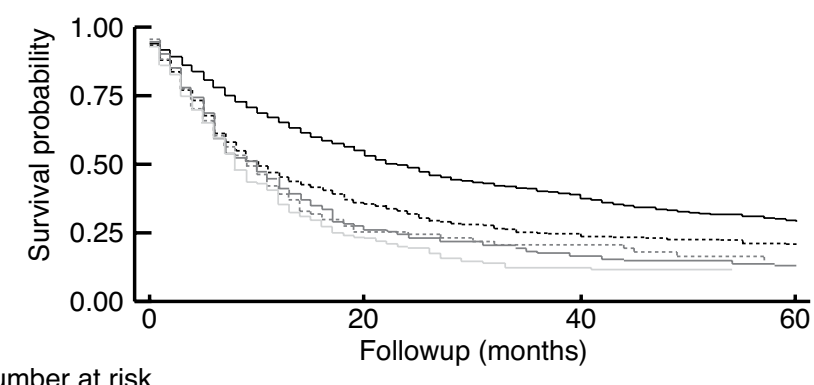

Number at risk
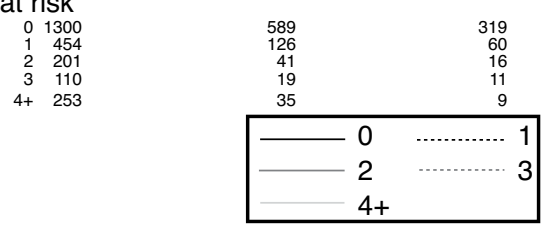

Fig. 2. Kaplan-Meier survival curves of cancer-specific survival for metastatic renal cell carcinoma patients stratified by the performance of lymphadenectomy (LND), defined as $(\boldsymbol{A}) \geq 1$ lymph node removed; $(\boldsymbol{B}) \geq 3$ lymph nodes removed; and $(\boldsymbol{C}) \geq 8$ lymph nodes removed among patients receiving cytoreductive nephrectomy, and by the (D) number of positive lymph nodes found for patients receiving lymphadenectomy, Surveillance, Epidemiology, and End Results registry $1988-2011$.

model includes risk factors that can be determined in a noninvasive fashion, but in a clinical trial setting, the number of positive LNs could also be useful to determine differential effects of treatment based on LN burden. Many authors note lack of evidence in performing LND in mRCC, but some suggest it could play a role for tyrosine kinase inhibitors, among other new systemic therapies. ${ }^{14}$ Therefore, level one evidence on the effect of LND on survival in mRCC could be readily obtained by randomizing the practice of LND into randomized control trials already planning to evaluate new systemic agents. ${ }^{15}$ Until then, if LND can be performed without increasing morbidity, select patients may benefit from this additional surgical extirpation.

The primary limitations of the present study, besides those already mentioned above, include its retrospective nature and lack of data on comorbidity and metastatic bur- den. Furthermore, data on the use of systemic agents is not available through SEER, allowing a finer level of association between improved survival over time and new treatments. However, the association of LND with survival was stable across a number of multivariable subset analyses, including time, and important sensitivity analyses were performed with different threshold definitions for LND. Despite the limitations, the results use a competing-risks analysis to demonstrate mortality trends for mRCC patients over a broad number of years and argue for a prognostic, rather than therapeutic role of LND in the management of mRCC.

\section{Conclusion}

In summary, mRCC continues to carry a poor prognosis, but current treatment paradigms invoking an integration of 
Patel et al.

surgical and systemic therapies have led to modest improvements in OS and CSS in recent years. Using a competingrisks approach, LND was found to play a prognostic rather than therapeutic role in the management of mRCC. The performance of LND should be limited based on clinical judgment and better incorporated into randomized trials of new systemic therapies to identify scenarios where implementation may improve survival.

Competing interests: Dr. Pierorazio is an unpaid member of the kidney cancer advisory board for Myriad Genetics. The remaining authors report no competing personal or financial interests.

Acknowledgement: This project was supported, in part, by the Predoctoral Clinical Research Training Program and the Johns Hopkins Institute for Clinical and Translational Research (ICTR), which is funded in part by Grant Number ULI TR 000424-06 from the National Center for Advancing Translational Sciences (NCATS) a component of the National Institutes of Health (NIH), and NIH Roadmap for Medical Research. Its contents are solely the responsibility of the authors and do not necessarily represent the official view of the Johns Hopkins ICTR, NCATS, or NIH.

This paper has been peer-reviewed.

\section{References}

1. Gupta K, Miller JD, Li JZ, et al. Epidemiologic and socioeconomic burden of metastatic renal cell carcinoma (mRCC): A literature review. Cancer Treat Rev 2008;34:193-205. http://dx.doi.org/10.1016/i. ctrv.2007.12.001

2. Kenney PA, Wood CG. Integration of surgery and systemic therapy for renal cell carcinoma. Urol Clin North Am 2012;39:211-31, vii. http://dx.doi.org/10.1016/i.ucl.2012.01.005

3. Mickisch GH, Garin A, van Poppel H, et al. Radical nephrectomy plus interferon-alfa-based immunotherapy compared with interferon alfa alone in metastatic renal-cell carcinoma: A randomized trial. Lancet 2001;358:966-70. http://dx.doi.org/10.1016/S0140-6736(01)06103-7

4. Flanigan RC, Salmon SE, Blumenstein BA, et al. Nephrectomy followed by interferon alfa-2b compared with interferon alfa-2b alone for metastatic renal cell cancer. N Engl J Med 2001;345:1655-9. http://dx.doi.org/10.1056/NEJMoa003013

5. Flanigan RC, Mickisch $G$, Sylvester $R$, et al. Cytoreductive nephrectomy in patients with metastatic renal cancer: A combined analysis. J Urol 2004;171:1071-6. http://dx.doi.org/10.1097/01. ju. 0000110610.61545 .ae

6. Russo $P, O^{\prime} B$ rien MF. Surgical intervention in patients with metastatic renal cancer: Metastasectomy and cytoreductive nephrectomy. Urol Clin North Am 2008;35:679-86; viii. http://dx.doi.org/10.1016/i. ucl.2008.07.009

7. Culp SH, Tannir NM, Abel EJ, et al. Can we better select patients with metastatic renal cell carcinoma for cytoreductive nephrectomy? Cancer 2010;116:3378-88. http://dx.doi.org/10.1002/cncr.25046

8. Jamal JE, Jarrett TW. The current role of lymph node dissection in the management of renal cell carcinoma. Int J Surg Oncol 2011;2011:816926.

9. Blom JH, van Poppel H, Maréchal JM, et al. Radical nephrectomy with and without lymph-node dissection: Final results of European Organization for Research and Treatment of Cancer (EORTC) randomized phase 3 trial 30881. Eur Urol 2009;55:28-34. http://dx.doi.org/10.1016/i.eururo.2008.09.052

10. Feuerstein $M A$, Kent $M$, Bernstein $M$, et al. Lymph node dissection during cytoreductive nephrectomy: A retrospective analysis. Int I Urol 2014;21:874-9. http://dx.doi.org/10.1111/iju.12457

11. Liungberg B. The role of metastasectomy in renal cell carcinoma in the era of targeted therapy. Curr Urol Rep 2013;14:19-25. http://dx.doi.org/10.1007/s1 1934-012-0293-6

12. Pantuck AJ, Zisman A, Dorey F, et al. Renal cell carcinoma with retroperitoneal lymph nodes: Role of lymph node dissection. J Urol 2003;169:2076-83. http://dx.doi.org/10.1097/01.ju.0000066130.27119.1c

13. Heng DY, Xie W, Regan MM, et al. External validation and comparison with other models of the International Metastatic Renal-Cell Carcinoma Database Consortium prognostic model: A populationbased study. Lancet Oncol 2013;14:141-8. http://dx.doi.org/10.1016/S1470-2045(12)70559-4
14. Capitanio U, Becker $F$, Blute ML, et al. Lymph node dissection in renal cell carcinoma. Eur Urol 2011;60:1212-20. http://dx.doi.org/10.1016/i.eururo.2011.09.003

15. Tsao CK, Small AC, Kates M, et al. Cytoreductive nephrectomy for metastatic renal cell carcinoma in the era of targeted therapy in the United States: A SEER analysis. World J Urol 2013;31:1535-9. http://dx.doi.org/10.1007/s00345-012-1001-3

Correspondence: Dr. Hiten Patel, James Buchanan Brady Urological Institute, Johns Hopkins Medical Institutions, Baltimore, MD, United States; hitenpate|@jhmi.edu

\section{Appendix A. Demographics, tumour characteristics, and intervention data for patients with metastatic renal cell carcinoma, SEER 1988-2011}

\begin{tabular}{|c|c|c|c|c|}
\hline & \multicolumn{2}{|c|}{ All $\mathrm{mRCC}$} & \multicolumn{2}{|c|}{$\begin{array}{l}\text { Cytoreductive } \\
\text { nephrectomy }\end{array}$} \\
\hline & Value & $\%$ or SD & Value & $\%$ or SD \\
\hline Overall & 15060 & 100.0 & 6316 & 100.0 \\
\hline \multicolumn{5}{|l|}{ Age (SD) } \\
\hline Mean & 62.9 & 12.1 & 60.16 & 11.2 \\
\hline$<45$ & 900 & 6.0 & 485 & 7.7 \\
\hline $45-54$ & 2851 & 18.9 & 1489 & 23.6 \\
\hline $55-64$ & 4524 & 30.0 & 2095 & 33.2 \\
\hline $65-74$ & 4009 & 26.6 & 1570 & 24.9 \\
\hline $75-84$ & 2297 & 15.3 & 634 & 10.0 \\
\hline $85+$ & 479 & 3.2 & 43 & 0.7 \\
\hline \multicolumn{5}{|l|}{ Sex } \\
\hline Male & 10133 & 67.3 & 4331 & 68.6 \\
\hline \multicolumn{5}{|l|}{ Race } \\
\hline White & 10818 & 71.8 & 4665 & 73.9 \\
\hline Black & 1385 & 9.2 & 457 & 7.2 \\
\hline Hispanic & 1889 & 12.5 & 785 & 12.4 \\
\hline Other & 968 & 6.4 & 409 & 6.5 \\
\hline $\begin{array}{l}\text { Lymph nodes } \\
\text { sampled }\end{array}$ & 2318 & 15.4 & 2318 & 36.7 \\
\hline $\begin{array}{l}\text { Cytoreductive } \\
\text { nephrectomy }\end{array}$ & 6316 & 41.9 & 6316 & 100.0 \\
\hline \multicolumn{5}{|l|}{ Radiation } \\
\hline None & 10055 & 66.8 & 4576 & 72.5 \\
\hline Therapy & 4855 & 32.2 & 1676 & 26.5 \\
\hline Unknown & 150 & 1.0 & 64 & 1.0 \\
\hline \multicolumn{5}{|c|}{ Tumour size $(\mathrm{cm})$} \\
\hline$\leq 4$ & 1232 & 8.2 & 445 & 7.0 \\
\hline$>4$ to $\leq 7$ & 3170 & 21.0 & 1413 & 22.4 \\
\hline$>7$ to $\leq 10$ & 3862 & 25.6 & 2027 & 32.1 \\
\hline$>10$ to $\leq 20$ & 3601 & 23.9 & 2029 & 32.1 \\
\hline$>20$ & 165 & 1.1 & 98 & 1.6 \\
\hline Unknown & 3029 & 20.1 & 304 & 4.8 \\
\hline \multicolumn{5}{|l|}{ Fuhrman grade } \\
\hline 1 & 331 & 2.2 & 152 & 2.4 \\
\hline 2 & 1611 & 10.7 & 1126 & 17.8 \\
\hline 3 & 3105 & 20.6 & 2186 & 34.6 \\
\hline 4 & 1626 & 10.8 & 1345 & 21.3 \\
\hline Unknown & 8387 & 55.7 & 1507 & 23.9 \\
\hline
\end{tabular}

mRCC: metastatic renal cell carcinoma; SEER: Surveillance, Epidemiology, and End Results registry; SD: standard deviation. 


\begin{tabular}{|c|c|c|}
\hline \multicolumn{3}{|c|}{$\begin{array}{l}\text { Appendix B. Number of lymph nodes removed at } \\
\text { lymphadenectomy and number of positive lymph nodes, } \\
\text { SEER 1988-2011 }\end{array}$} \\
\hline & Value & $\%$ \\
\hline Cohort & 15060 & 100.0 \\
\hline \multicolumn{3}{|l|}{ \# LNs sampled } \\
\hline 0 & 12742 & 84.6 \\
\hline 1 & 689 & 4.6 \\
\hline 2 & 339 & 2.3 \\
\hline 3 & 222 & 1.5 \\
\hline 4 & 165 & 1.1 \\
\hline $5-10$ & 490 & 3.3 \\
\hline $11-25$ & 329 & 2.2 \\
\hline$>25$ & 84 & 0.6 \\
\hline \multicolumn{3}{|l|}{ Mean (SD) } \\
\hline Overall & 0.9 & 3.8 \\
\hline If $L N$ removed & 6.2 & 7.9 \\
\hline Any LN removed & 2318 & 15.4 \\
\hline Any positive node(s) & 1018 & 6.8 \\
\hline \multicolumn{3}{|l|}{ \# LNs positive } \\
\hline 0 & 1300 & 8.6 \\
\hline 1 & 454 & 3.0 \\
\hline 2 & 201 & 1.3 \\
\hline 3 & 110 & 0.7 \\
\hline 4 & 60 & 0.4 \\
\hline $5-10$ & 138 & 0.9 \\
\hline$>10$ & 55 & 0.4 \\
\hline Mean (SD) & 1.4 & 3.3 \\
\hline If any positive LN & 3.3 & 4.3 \\
\hline$\%$ positive nodes & $32.4 \%$ & - \\
\hline
\end{tabular}

\begin{tabular}{|c|c|c|c|c|}
\hline \multicolumn{5}{|c|}{$\begin{array}{l}\text { Appendix C. Cox proportional hazards competi } \\
\text { risks regression models among patients under } \\
\text { lymphadenectomy for associations with cance } \\
\text { survival, SEER 1988-2011 }\end{array}$} \\
\hline 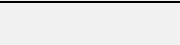 & \multicolumn{4}{|c|}{$95 \% \mathrm{Cl}$} \\
\hline & HR $^{\mathrm{a}}$ & Low & High & p value \\
\hline \multicolumn{5}{|l|}{ Positive LNs } \\
\hline 0 & REF & - & - & - \\
\hline 1 & 1.56 & 1.37 & 1.77 & $<0.001$ \\
\hline 2 & 1.96 & 1.66 & 2.33 & $<0.001$ \\
\hline 3 & 1.78 & 1.41 & 2.25 & $<0.001$ \\
\hline $4+$ & 2.30 & 1.96 & 2.7 & $<0.001$ \\
\hline \multicolumn{5}{|l|}{ Age } \\
\hline$<45$ & REF & - & - & - \\
\hline $45-54$ & 0.92 & 0.77 & 1.11 & 0.40 \\
\hline $55-64$ & 0.96 & 0.81 & 1.15 & 0.69 \\
\hline $65-74$ & 1.02 & 0.84 & 1.23 & 0.84 \\
\hline $75-84$ & 1.26 & 0.99 & 1.60 & 0.06 \\
\hline $85+$ & 1.28 & 0.65 & 2.52 & 0.48 \\
\hline \multicolumn{5}{|l|}{ Sex } \\
\hline Female & 1.10 & 0.99 & 1.23 & 0.06 \\
\hline \multicolumn{5}{|l|}{ Race } \\
\hline White & REF & - & - & - \\
\hline Black & 1.23 & 1.02 & 1.48 & 0.03 \\
\hline Hispanic & 0.93 & 0.80 & 1.07 & 0.30 \\
\hline Other & 0.86 & 0.70 & 1.06 & 0.16 \\
\hline \multicolumn{5}{|l|}{ Radiation } \\
\hline None & REF & - & - & - \\
\hline Therapy & 1.36 & 1.21 & 1.53 & $<0.001$ \\
\hline Unknown & 1.55 & 0.98 & 2.45 & 0.06 \\
\hline \multicolumn{5}{|l|}{ Tumour size } \\
\hline$\leq 4$ & REF & - & - & - \\
\hline$>4$ to $\leq 7$ & 0.92 & 0.72 & 1.19 & 0.54 \\
\hline$>7$ to $\leq 10$ & 1.09 & 0.86 & 1.38 & 0.48 \\
\hline$>10$ to $\leq 20$ & 1.12 & 0.89 & 1.42 & 0.34 \\
\hline$>20$ & 1.50 & 1.02 & 2.20 & 0.04 \\
\hline Unknown & 0.98 & 0.65 & 1.49 & 0.94 \\
\hline
\end{tabular}

${ }^{a}$ Multivariable Cox model adjusted for year (not shown), cytoreductive nephrectomy, age, sex, race, radiation, and tumour size. Cl: confidence interval; $\mathrm{CN}$ : cytoreductive

nephrectomy HR: hazard ratio; LN: Iymph node. SEER: Surveillance, Epidemiology, and End Results registry. 